\title{
ARTICLE
}

\section{All About That Base: Investigating the Role of Ligand Basicity in Pyridyl Complexes Derived from a Copper-Schiff Base Coordination Polymer}

Received 00th January 20xx, Accepted 00th January 20xx DOI: $10.1039 / x 0 \times x 00000 x$
Samuel V. F. Beddoe, ${ }^{a}$ Rhona F. Lonergan, ${ }^{\mathrm{b}}$ Mateusz Pitak, ${ }^{\mathrm{a}}$ Jason R. Price, ${ }^{\mathrm{c}}$ Simon J. Coles, ${ }^{\text {a Jonathan }}$ A. Kitchen ${ }^{d}$ and Tony D. Keene ${ }^{a, b, *}$

\begin{abstract}
The role of ligand basicity in complex formation has been investigated using monodentate pyridines or benzimidazole ( $\mathbf{M}$ ) in combination with a solution-stable species derived form a coordination polymer, [Cu(L)] (where $\mathbf{L}=2-(2-$ hydroxybenzylidene-amino)phenol). The $12\left[\mathrm{Cu}(\mathbf{L})(\mathbf{M})_{n}\right]$ complexes generated, combined with the $[\mathrm{Cu}(\mathbf{L})]_{2}(\mathbf{P})$ complexes from our previous work (where $\mathbf{P}$ is a polypyridyl ligand), allow us to gauge the likelihood of complex formation based on the $p \mathrm{~K}_{a}$ of the conjugate acid of the pyridyl ligands and Hammett parameter, $\sigma$. Above $\mathrm{p} K_{\mathrm{a}} \approx 4.5$, complexes are formed where the only ligands are $\mathbf{L}^{2-}$ and $\mathbf{M}$ or $\mathbf{P}$ and the packing interactions are predominantly van der Waals. Below this value, complex formation is unlikely unless there additional oxygen ligands in the $d_{z^{2}}$ of the $\mathrm{Cu}(\mathrm{II})$ ion. The structures of two literature $[\mathbf{C u}(\mathbf{L})(\mathbf{B})]$ complexes, where $\mathbf{B}$ is a chelating bidentate pyridyl ligand are also re-examined to resolve the disorder in the $[\mathrm{Cu}(\mathrm{L})]$ moiety.
\end{abstract}

\section{Introduction}

Pyridyl ligands are some of the most ubiquitous in coordination chemistry. Ligands such as 2,2'-bipyridine and 1,10phenanthroline ${ }^{1,2}$ are the archetypal pyridyl chelators and 4,4'bipyridine is a classic bridging molecule. ${ }^{3}$ As pyridines are readily functionalised, a wide range of different members of this family exist. 4,5 The size of this family gives coordination chemists a large variety of ligands to explore when constructing pyridyl complexes for catalysis, ${ }^{6-8}$ spin crossover, $^{9,10}$ molecular magnets, ${ }^{11,12}$ coordination polymers, ${ }^{13-15}$ metal-organic frameworks, ${ }^{16,17}$ medical imaging and therapeutic agents. ${ }^{18,19}$

In our previous work, ${ }^{20}$ we investigated the role of solubility of polypyridyl ligands $(\mathbf{P})$ in the construction of coordination polymers and complexes synthesised from a copper Schiff-base starting material, $\left\{[\mathrm{Cu}(\mathrm{L})]_{2}\right\}_{n}$, (compound $\mathbf{1}$, where $\mathbf{L}=2-[(2-$ hydroxybenzylidene)amino]phenol. Compound $\mathbf{1}$ is a onedimensional coordination polymer that can dissolve in DMSO to give $\left[\mathrm{Cu}(\mathrm{L})(\mathrm{DMSO})_{n}\right]$ 'coordination monomer' complexes in solution. Combined with the bridging polypyridyls, this produced a range of $[\mathrm{Cu}(\mathbf{L})]_{2}(\mathbf{P})$ complexes. We established that

a. School of Chemistry, University of Southampton, University Road, Highfield, Southampton, SO17 1BJ, UK.

b. School of Chemistry, University College Dublin, Belfield 4, Dublin, Ireland.

c. Australian Synchrotron, 800 Blackburn Road, Clayton, Victoria 3168, Australia.

d. Chemistry, Institute for Natural and Mathematical Science, Massey University, Auckland, New Zealand.

† Electronic Supplementary Information (ESI) available: Experimental conditions; crystallographic parameters; full crystal structure descriptions, tabulation of $\mathrm{p} K_{\mathrm{a}}$ and Hammett values, calculation of Hammett equation for pyridines. See DOI: $10.1039 / x 0 \times x 00000 x$ if the polypyridyl has a lower solubility than compound $\mathbf{1}$, then complex formation did not proceed, placing a limit on the utility of polypyridyl bridges in this system.

We then turned our attention to monopyridyl ligands (M). The original 1937 paper on $\left\{[\mathrm{Cu}(\mathrm{L})]_{2}\right\}_{n}{ }^{21}$ also describes the synthesis of a pyridine complex, $[\mathrm{Cu}(\mathbf{L})(\mathrm{py})](\mathbf{2})$. Two groups reported a partially-resolved structure of compound $\mathbf{2}$ in the $1990 \mathrm{~s}^{22,23}$ and complexes of $[\mathrm{Cu}(\mathrm{L})]$ were reported with the chelating polypyridines terpyridine ${ }^{24}$ and phenanthroline, the latter with methanol, ${ }^{25}$ and water $^{26}$ solvates. A further report of an imidazole complex, $[\mathrm{Cu}(\mathrm{L})(\mathrm{im})]$ showed that other heterocyclic ligands could be used in place of pyridines, this time with full resolution of the $[\mathrm{Cu}(\mathrm{L})]$ moiety. ${ }^{26}$

However, no systematic study has been undertaken to date on the coordination of monopyridines to $[\mathrm{Cu}(\mathrm{L})]$ and we set out to determine what factors influence the ability of monopyridines to act as ligands for $[\mathrm{Cu}(\mathrm{L})]$. As ligands are Lewis bases,
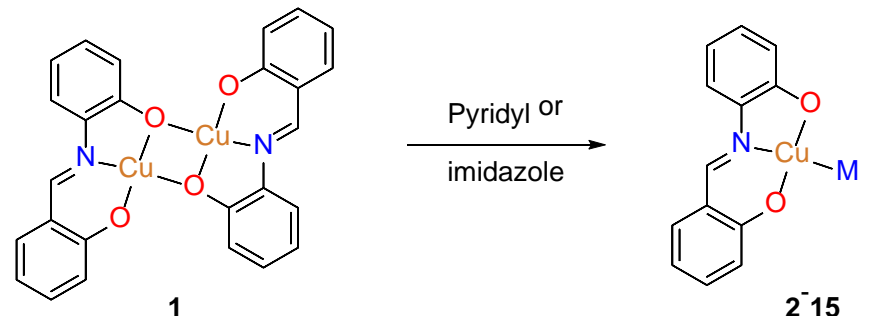

Scheme 1 Formation of $\left[\mathrm{Cu}(\mathbf{L})(\mathbf{M})_{n}\right]$ complexes $(\mathbf{2 - 1 5})$ from $\left\{[\mathrm{Cu}(\mathbf{L})]_{2}\right\}_{n}(\mathbf{1})$ where $M$ is a pyridyl or imidazole ligand. 


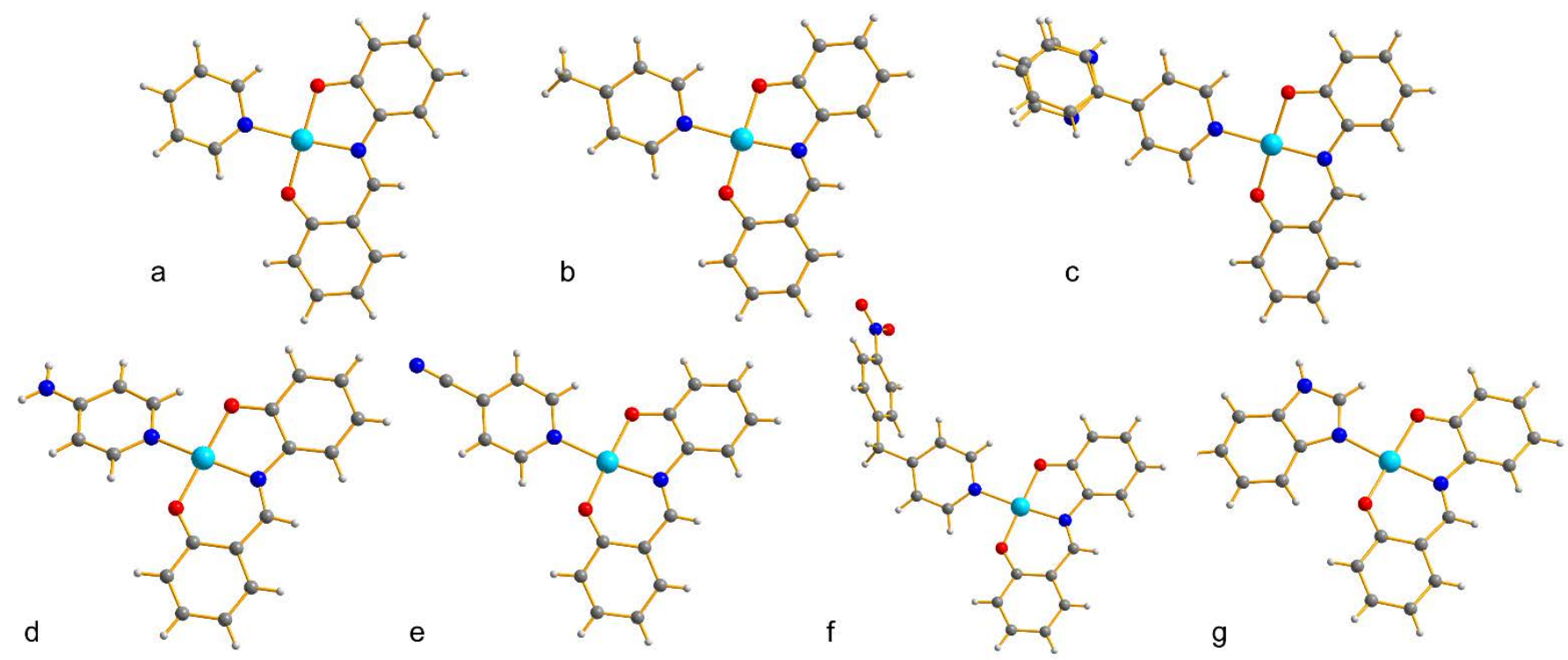

Figure 1: [Cu(L)](M) units for a) $\mathbf{2}(\mathbf{M}=$ py); b) $\mathbf{4}$ ( $\mathbf{M}=4$-pico); c) $\mathbf{6}(\mathbf{M}=\mathbf{2 , 4}$ '-bipy); d) $\mathbf{7}$ ( $\mathbf{M}=4$-ampy); e) $\mathbf{1 0}$ ( $\mathbf{M}=\mathbf{4}$-cnpy); f) $\mathbf{1 1}$ ( $\mathbf{M}=4$-nbpy) and g) $\mathbf{1 2}$ ( $\mathbf{M}=$ = bnz). The minor [Cu(L)] unit is omitted for clarity.

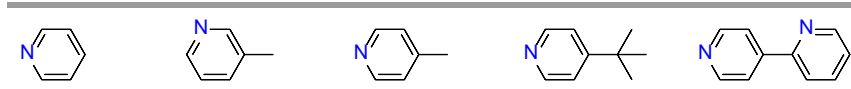

py (2) $5.23 \quad$ 3-pico (3) $5.68 \quad 4$-pico (4) $6.02-4$-tbpy (5) 5.99

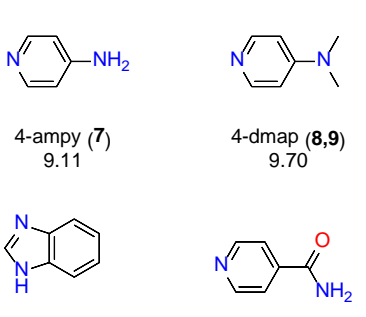

$\operatorname{bnz}(\mathbf{1 2}) 5.4$

$$
\text { 4-inam (13) } 3.61
$$
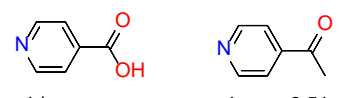

4-acpy 3.51

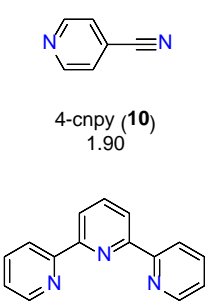

tpy (14) 4.69

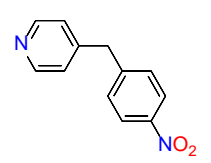

4-nbpy (11) ((5.17))

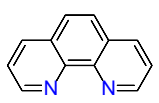

phen (15) 4.98 4-inac [1.77]

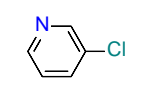

3-pycl 2.84

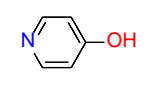

4-pyoh [3.27]

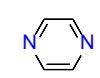

pyz 1.10
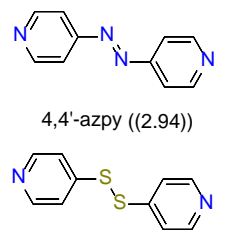

4,4'-dtpy 4.80

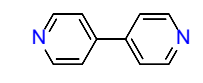

4,4'-bipy 4.82

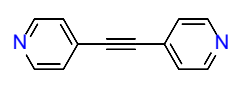

$4,4^{\prime}-\operatorname{bpac}((4.62))$

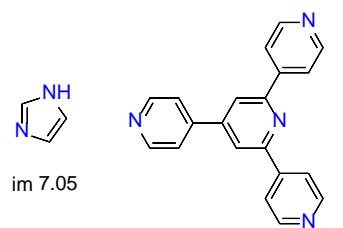

4,4,4"'-tppy ((4.82, 4.77))

Scheme 2 Ligands used in this study and from previous work along with their $\mathrm{p} K_{\mathrm{a}}$ values. Numbers in bold refer to complexes formed with [Cu(L)] in this work. $\mathrm{p} K_{\mathrm{a}}$ values in square brackets are that for more acidic protons (e.g. $-\mathrm{OH}$ from Hammett parameters or analogous phenyl compounds.

substituents on the pyridyl ring will affect the ability of the ligand lone pair to coordinate to the $\mathrm{Cu}(\mathrm{II})$ centre and two parameters were investigated to this end: 1) the pKa of the protonated pyridine and 2) the Hammett parameter, $\sigma$, of the substituent.

\section{Results and Discussion}

\section{Synthesis}

Two synthetic strategies have been utilised: A) dissolution of compound $\mathbf{1}$ in a liquid pyridine, followed by either evaporation or diffusion of water vapour to form crystals and; B) dissolution of compound $\mathbf{1}$ and a solid pyridine in DMSO and crystallisation by diffusion of water vapour. In each case, crystals suitable for single-crystal $\mathrm{X}$-ray diffraction measurements were obtained. Full synthetic details are available in the ESI.

\section{Structure}

After our work on modelling the disorder in $[\mathrm{Cu}(\mathbf{L})]_{2}(\mathbf{P})$ systems, we decided to revisit $[\mathrm{Cu}(\mathrm{L})(\mathrm{py})](\mathbf{2})$ in order to resolve the structure (Figure 1a). Compound $\mathbf{2}$ crystallises in the orthorhombic space group $\mathrm{Pna}_{1}$ and consists of a $\mathrm{Cu}$ (II) that is coordinated by a double-deprotonated $\mathbf{L}$ group and a pyridine molecule. The $\mathbf{L}^{2-}$ group chelates the $\mathrm{Cu}(\mathrm{II})$ ion with a pyridine molecule binding opposite the $\mathrm{Cu}$-imine bond to complete a square plane. The short metal-ligand bonds indicate that these bonds occur in the $d_{x^{2}-y^{2}}$ orbital. No ligand atoms are seen to suggest coordination in the $d_{z^{2}}$. The complex is planar with a maximum deviation from the plane of $0.015 \AA$. As seen in our previous work and in the literature, the $[\mathrm{Cu}(\mathrm{L})]$ unit is disordered about an axis just off of the $\mathrm{Cu}-\mathrm{N}_{\text {imine }}$ bond in a 50:50 ratio. A full structure description of all complexes can be found in the ESI.

The method of synthesis of this compound differs from that of our previous work in that pyridine is used as the solvent and crystallisation is achieved by slow diffusion of water vapour into the reaction. This technique was used successfully for 3-pico (3, figure $2 \mathrm{a}$ ) which gave the same basic $[\mathrm{Cu}(\mathbf{L})(\mathbf{M})]$ unit except with an axial 3-pico ligand in the $d_{z^{2}}$ to give [Cu(L)(3-pico) 2$]$. 4-pico (4, figure $1 \mathrm{~b}$ ) was synthesised in the same way as $\mathbf{3}$, but gave a structure closely related to $\mathbf{2}$ in that a single 4-pico is bound to the $\mathrm{Cu}$ atom in the $d_{x^{2}-y^{2}}$ orbital, resulting in a planar [Cu(L)(4pico)] complex. Compound $\mathbf{5}$ is synthesised with 4-tbpy and gives a complex similar to $\mathbf{3}$ but required a modification to the 

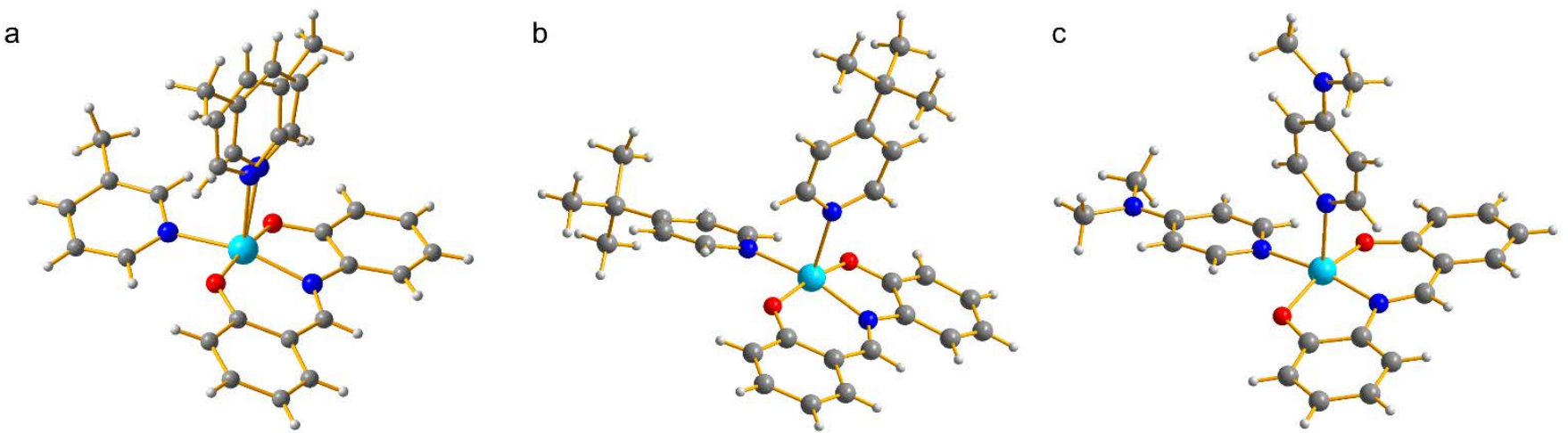

Figure $\mathbf{2}[\mathrm{Cu}(\mathbf{L})](\mathbf{M})_{2}$ units for a) $\mathbf{3}(\mathbf{M}=3-\mathrm{pico})$; b) $\mathbf{5}(\mathbf{M}=$ 4-tbpy) and c) $\mathbf{8}(\mathbf{M}=$ 4-dmap, polymorph 1). The minor [Cu(L)] unit is omitted for clarity.

synthesis due to the immiscibility of water and 4-t-butyl pyridine: $\left\{[\mathrm{Cu}(\mathrm{L})]_{2}\right\}_{n}$ readily dissolves in 4-tbpy and this solution was layered over water. The vial was then stood in a jar of isopropanol which slowly allowed the solutions to become miscible and large greenish black crystals of $[\mathrm{Cu}(\mathrm{L})](4-\mathrm{tbpy})_{2}(\mathbf{5}$, figure $2 \mathrm{~b}$ ) were formed. Compound 6 was formed by route B: dissolution of the ligand, 2,4'-bipy, in DMSO followed by slow diffusion of atmospheric water into the solution to lead to blackish-green crystals of $\left[\mathrm{Cu}(\mathrm{L})\left(2,4^{\prime}\right.\right.$-bipy $\left.)\right]$. The structure is similar to $\mathbf{2}$ except with the addition of a 2 -pyridine ring, which is disordered 50:50 through rotation of the bond between the pyridine rings. A modification of the synthetic method for 6 was used for 4-ampy, 4-dmap, 4-cnpy, 4-nbpy, bnz and 4-inam where an excess of ligand was used to counter their high solubility in DMSO. 4-ampy gave [Cu(L)](4-ampy) (7 figure $1 \mathrm{~d})$ in which the $[\mathrm{Cu}(\mathrm{L})]$ appeared to be ordered. To confirm this, the structure was collected again to $0.4 \AA$ resolution at which point disorder could be seen and resolved with a 96:4 ratio of components.

Following preparation route $B$, 4-dmap produced two polymorphs of $\left[\mathrm{Cu}(\mathrm{L})(4-\mathrm{dmap})_{2}\right]$. The first $(\mathbf{8}$, figure $2 \mathrm{c})$ contains a single $\left[\mathrm{Cu}(\mathrm{L})(4-d m a p)_{2}\right]$ unit with one planar and one axial 4dmap molecule. The second polymorph (9) contains three $\left[\mathrm{Cu}(\mathrm{L})(4-\mathrm{dmap})_{2}\right]$ units. The major differences between the polymorphs are that in $\mathbf{8}$ the axial ligand is almost perpendicular to the $d_{x^{2}-y^{2}}$ plane $\left(89.56^{\circ}\right.$ between the plane of the axial pyridine ring and the $d_{x^{2}-y^{2}}$ plane) while in 9, all three have different degrees of perpendicularity $\left(83.47^{\circ}\right.$ for Cu11, 53.76 for

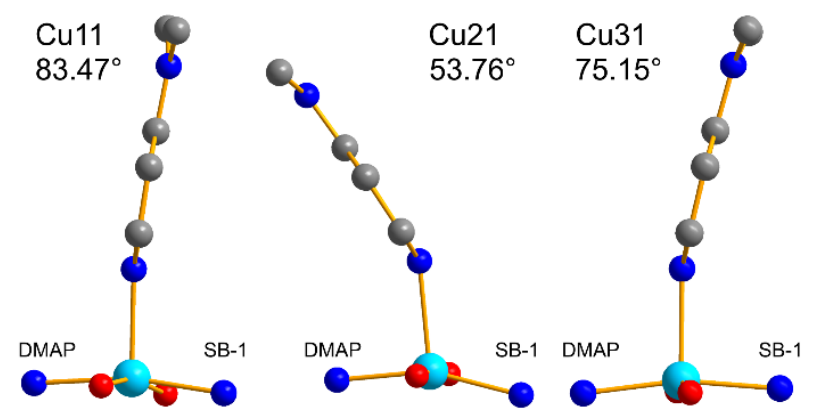

Figure 3 Degrees of perpendicularity for axial 4-dmap ligands with respect to the $\mathrm{CuN}_{2} \mathrm{O}_{2}$ plane for the three independent $\left[\mathrm{Cu}(\mathrm{L})(4-\mathrm{dmap})_{2}\right]$ units in compound 9 .
Cu21 and 75.15 for Cu31, figure 3). The unit cells of 8 and 9 were found at both $100 \mathrm{~K}$ and $293 \mathrm{~K}$, ruling out the possibility that there is a thermally-induced phase transition from one to the other.

In the majority of the compounds with axial pyridine ligands (3, 5 and 9), the plane of the pyridine is slightly off of the plane formed by the two oxygen atoms of $\mathrm{L}, \mathrm{Cu}$ and the nitrogen of the pyridine, indicating that the complexes may be stabilised through a $\mathrm{C}-\mathrm{H} \cdots \mathrm{O}$ interaction between the pyridine and the $[\mathrm{Cu}(\mathrm{L})]$ unit. Compound $\mathbf{8}$ is an exception where the plane of the pyridine instead aligns with the $\mathrm{CuN}_{3}$ plane (Figure 2c), providing an alternative route to stabilising the conformation of the complex.

4-cnpy gives a $[\mathrm{Cu}(\mathbf{L})(4-c n p y)]$ complex (10, figure $1 \mathrm{e})$, superficially similar to $\mathbf{2}$, but with the major difference in that the complexes dimerise through axial $\mathrm{Cu} \cdots \mathrm{O}$ interactions to a neighbouring unit (figure S14, ESI). 4-nbpy forms a complex similar to 2 (11, figure 2f).

A literature report of $\left[\mathrm{Cu}(\mathrm{L})(\text { imidazole) }]^{26}\right.$ encouraged us to investigate the use of benzimidazole, which was successful and gave $[\mathrm{Cu}(\mathrm{L})(\mathrm{bnz})](\mathbf{1 2})$, resulting in a structure similar to the $[\mathrm{Cu}(\mathbf{L})(\mathbf{M})]$ complexes (figure $1 \mathrm{~g}$ ).

A complex was formed with isonicotinamide, but this required a modification to the procedure in that $30 \%$ water was added to the reaction mixture to give $\left[\mathrm{Cu}(\mathrm{L})\left(\mathrm{H}_{2} \mathrm{O}\right)(4\right.$-inam)]. DMSO (13). In this complex, the plane of the isonicotinamde is substantially deviated from planar (figure 4 ) with the $[\mathrm{Cu}(\mathrm{L})]$ unit $\left(66.3(6)^{\circ}\right)$,

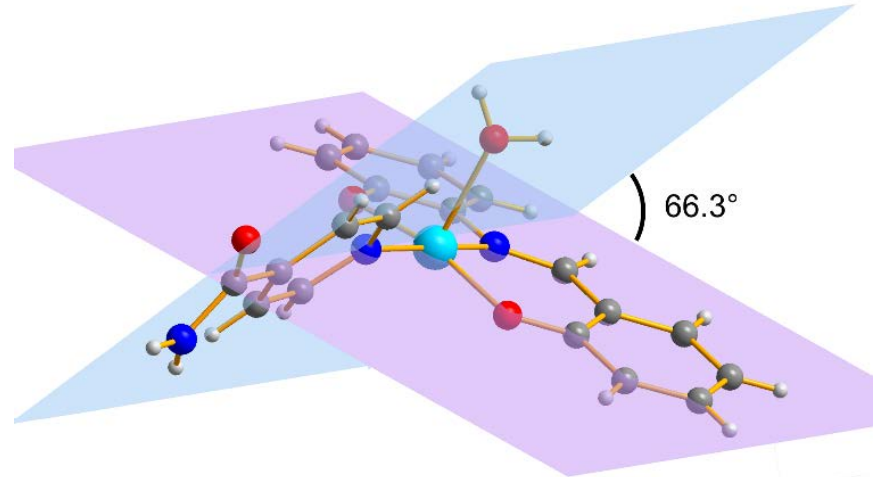

Figure 4 Deviation from planarity of pyridine ligand (blue plane) and $[\mathrm{Cu}(\mathrm{L})]$ unit (purple plane) in $\left[\mathrm{Cu}(\mathrm{L})\left(\mathrm{H}_{2} \mathrm{O}\right)(4\right.$-inam)].DMSO (13). 

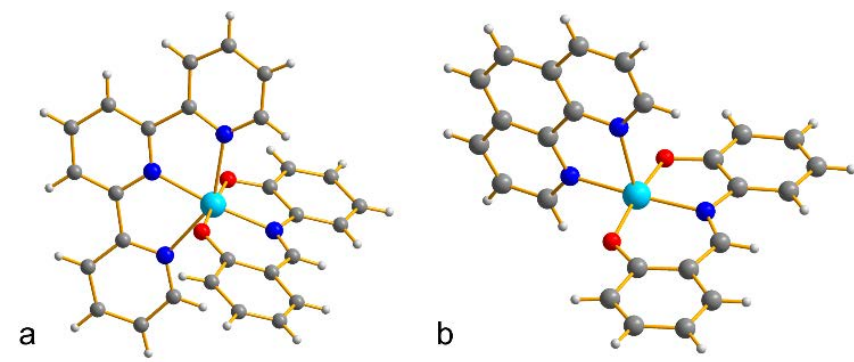

Figure $5[\mathrm{Cu}(\mathbf{L})](\mathbf{B})$ complexes with chelating ligands a) $\mathbf{1 4}(\mathbf{B}=$ tpy) and b) $\mathbf{1 5}(\mathbf{B}=$ phen). The minor $[\mathrm{Cu}(\mathrm{L})]$ unit is omitted for clarity.

unlike the majority of those above. The water molecule is bound axially to the $\mathrm{Cu}$ atom and the resultant $\left[\mathrm{Cu}(\mathrm{L})\left(\mathrm{H}_{2} \mathrm{O}\right)(4\right.$-inam)] unit is built into the 3D structure through a complex system of hydrogen bonding between $\mathrm{H}_{2} \mathrm{O}$, DMSO and isonicotinamide, indicating that in this case, the stability of the complex is more heavily dependent on the interaction with other molecules in the structure.

At this point, we decided to re-investigate two reports of chelating ligands, B, with $[\mathrm{Cu}(\mathrm{L})]$ : tpy ${ }^{24}$ and phen. ${ }^{25}$ The method of synthesis of $[\mathrm{Cu}(\mathrm{L})(\mathrm{tpy})](\mathbf{1 4}$, figure $5 \mathrm{a})$ was the same as the original report and gave black crystals. This route was utilised for $[\mathrm{Cu}(\mathrm{L})(\mathrm{phen})] .3 \mathrm{MeOH}(\mathbf{1 5}$, figure $5 \mathrm{~b})$ instead of the original electrochemical synthesis. We were able to determine that in both the $\mathrm{Cu}$ atom was not split over two sites while the $\mathbf{L}$ ligand was disordered and were able to resolve this successfully in both compounds. This is likely due to the effect of the chelating ligands anchoring the $\mathrm{Cu}$ in place. In $\mathbf{1 5}$, the $\mathrm{Cu}$ atom is on a twofold rotation axis whereas none of the other compounds have a symmetry element in the $[\mathrm{Cu}(\mathrm{L})]$ unit. The heavily disordered $\mathrm{MeOH}$ molecules in $\mathbf{1 5}$ were excluded from the refinement using SQUEEZE, which gave an electron density in the voids consistent with the three $\mathrm{MeOH}$ molecules found by elemental analysis in the original report.

\section{Discussion}

Combining the results of literature reports, our previous work into $[\mathrm{Cu}(\mathbf{L})]_{2}(\mathbf{P})$ (where $\mathbf{P}$ is a bridging polypyridine) and this work, it can be seen that a wide range of pyridyl and imidazole compounds can act as ligands for the $[\mathrm{Cu}(\mathrm{L})]$ unit. We also found a number of pyridines were not successful. Tabulating the $p K_{a}$ of protonated monopyridines ${ }^{27}$ (Figure 6, Table S3) revealed that where data is known, there appears to be a cut off around $\mathrm{p} K_{\mathrm{a}} \approx 4.5$, under which only two pyridines formed complexes. Above 4.5, $\left[\mathrm{Cu}(\mathrm{L})(\mathrm{M})_{n}\right]$ complexes form where van der Waals interactions predominate and the coordination sphere consists only of $\mathbf{L}^{2-}$ and $\mathbf{M}$ ligands. Below this, either no complex was formed, resulting in the re-precipitation of compound $\mathbf{1}$ or complexes formed where there are axial oxygen ligands, either as water (compound 13, 4-inam) or from dimerisation of $[\mathrm{Cu}(\mathbf{L})(\mathbf{M})]$ (compound 10, 4-cnpy). From this, we can infer that the more basic the pyridine, the more likely it is to form a complex without stabilisation from coordination to solvent or dimerisation. While this is a useful guideline, $\mathrm{p} K_{\mathrm{a}}$ data for monopyridines is somewhat scant. We next looked at the
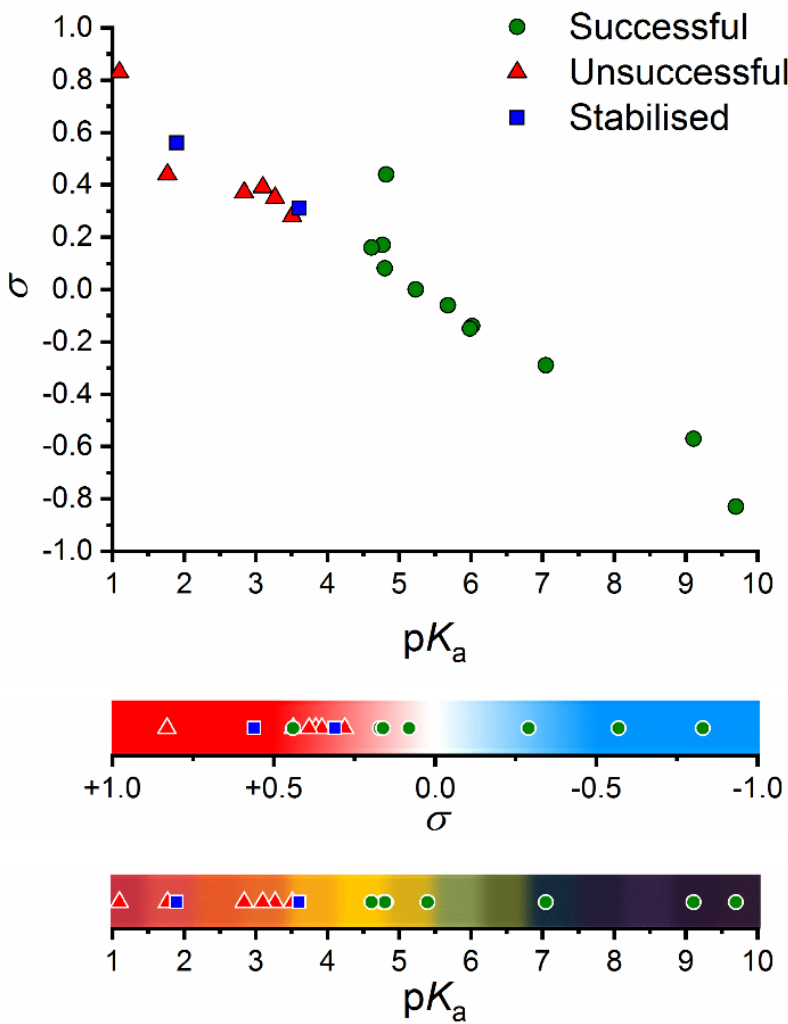

Figure 6 Top: Inverse Hammett plot for pyridyl ligands used in this study. Green circles represent ligands successfully forming complexes with [Cu(L)] without further species; blue squares represent ligands forming complexes with [Cu(L)] where additional oxygen species occur in the Jahn-Teller axis; red triangles represent ligands where $\left\{[\mathrm{Cu}(\mathrm{L})]_{2}\right\}_{n}$ recrystallises without complex formation.

Hammett parameters, ${ }^{28,29} \sigma$, of the pyridine substituents, with corrections applied for pyridines. ${ }^{29}$ Generally, if $\sigma<0.2$, then we see simple complex formation, i.e. that this model works for electron-donating or mildly electron-withdrawing groups. Above $\mathbf{0 . 2}$, then either compound 1 re-precipitates or stabilised complexes are formed. The one outlier is $4,4^{\prime}$-bipyridine. As Hammett parameters are derived from the $\mathrm{p} K_{\mathrm{a}}$ of substituted benzoic acids, corrections are applied in some cases for pyridines $^{29}$ as mesomeric effects in benzoates do not necessarily appear in the analogous pyridine.

Considerably more Hammett parameters have been reported than $\mathrm{p} K_{\mathrm{a}}$ values for pyridines, which enables us to evaluate the suitability of pyridine ligands in this work. However, there are still many compounds where neither value is known. Approximate Hammett parameters can be calculated, as outlined by Perrin et $a .^{29}$ by comparison with known substituent groups and by including transmission effects where linking groups are introduced. From the Hammett parameter, a $\mathrm{p} K_{\mathrm{a}}$ value may be calculated for a pyridine. We have been able to update the Hammett equation for pyridines from the original by Clark and Perrin ${ }^{30}$ using a wider range of values (Table S3 and Figure S25, ESI) to give equation 1:

$$
\mathrm{p} K_{\mathrm{a}}=5.23-5.46 \Sigma \sigma \quad \text { eq. } 1
$$

We tested the procedure by estimating $\sigma$ for 4-dtdp (+0.08) which gave $\mathrm{p} K_{\mathrm{a}}=4.79$, which is within $0.01 \mathrm{p} K_{\mathrm{a}}$ units of the 
reported literature value of $4.80 . .^{31}$ Using this route, we can predict a Hammett parameter for 4-nbpy of +0.01 and a $\mathrm{p} K_{\mathrm{a}}$ of 5.18 , which corresponds well with the formation of compound 11.

In three cases, we could approximate the $\mathrm{p} K_{\mathrm{a}}$ and $\sigma$ of a polypyridine ligand by comparison to the compounds where a phenyl took the place of the second pyridine. Thus, we can estimate the $\mathrm{p} K_{\mathrm{a}}$ of $4,4^{\prime}$-azpy as 3.10 , outside of the range of successful $\mathrm{p} K_{\mathrm{a}}$ values. As predicted, no complex was formed with 4,4'-azpy, with only compound 1 recrystallising from DMSO. 4,4'-azpy is quite soluble in DMSO, thus the lack of complex formation is attributed to the low basicity of the ligand rather than to the difference in solubility between the bridging ligand and compound 1, as shown in our previous work. 4,4'bpac was estimated to have a $\mathrm{p} K_{\mathrm{a}}$ of 4.62 by comparison to the 4-(phenylethynyl)pyridine ${ }^{32}$ and successfully forms a complex. $4,4^{\prime}, 4^{\prime \prime}$-tppy is similar to both $4,4^{\prime}$-bipy and $2,4^{\prime}$-bipy and thus complex formation would be expected, as we reported previously.

Monopyridines such as 3-pycl and 4-acpy also have $\mathrm{p} K_{\mathrm{a}}$ values below that of the successful complexes (2.84 and 3.51, respectively) and no complex was formed when synthesis was attempted. 4-pyoh and 4-inac both have acidic protons, which may well preclude complex formation $\left(p K_{a}=3.27\right.$ and 1.77 , respectively). The chelating polypyridines phen and tpy gain some addition stability through the chelation effect, but the $\mathrm{p} K_{\mathrm{a}}$ of both is above the cut-off value (4.98 and 4.69, respectively). Effective $\sigma$ values can be estimated for aza-heterocycles such pyrazine and imidazole, both of which lie along the line of $\mathrm{p} K_{\mathrm{a}}$ vs $\sigma$ for pyridines. ${ }^{29}$ Estimating $\sigma$ for benzimidazole using the same heterocycle technique gives a value $1 \mathrm{p} K_{\mathrm{a}}$ unit more basic than the measured value, a problem that is also seen in pteridines. ${ }^{29}$

As mentioned above, 4,4'-bipy is an outlier in terms of $\sigma$. Using eq. 1 , we can calculate a corrected $\sigma$ value of $+0.08\left(p K_{a}=4.82\right)$ compared to the literature value of +0.44 for $4-(4-$ pyridyl)benzoic acid. This corrected value should be used where resonance stabilisation of a negative charge on the 4-pyridyl nitrogen does not occur. 4,4'-bipy forms two different compounds with $[\mathrm{Cu}(\mathrm{L})]$ - one with stabilisation similar to compound $\mathbf{1 0}$ where axial $\mathrm{Cu} \cdots \mathrm{O}$ bonds form a two-dimensional coordination polymer and another, $[\mathrm{Cu}(\mathrm{L})]\left(4,4^{\prime}\right.$-bipy).4DMSO where there is no axial bond formation despite the presence of DMSO molecules. This indicates that the true nature of 4,4'bipyridine in this system may lie somewhere near the cut-off and may have a slightly higher Hammett parameter than predicted by $\mathrm{p} K_{\mathrm{a}}$ alone.

An interesting result of the relationship of $\mathrm{p} K_{\mathrm{a}}$ to complex formation is that we can postulate an "effective $\mathrm{p} K_{\mathrm{a}}$ " for the $[\mathrm{Cu}(\mathrm{L})]$ unit itself. At $\mathrm{p} K_{\mathrm{a}}$ values below 4.6, compound 1 is reformed from the $\left[\mathrm{Cu}(\mathrm{L})(\mathrm{DMSO})_{n}\right]$ solution species, indicating that the pyridine ligand must have a higher degree of coordinating ability than another $[\mathrm{Cu}(\mathrm{L})]$ unit. As such, $[\mathrm{Cu}(\mathrm{L})]$ must have an effective $\mathrm{p} K_{\mathrm{a}}$ value between that of $4,4^{\prime}$-bpac (4.62) and 4-inam (3.61).

\section{Conclusion}

Combining the results of this work with that of previously reported complexes allows prediction of complex formation in the $[\mathrm{Cu}(\mathrm{L})]$ system based on two criteria: a) solubility of the ligand compared to that of the $\left\{[\mathrm{Cu}(\mathrm{L})]_{2}\right\}_{n}$ starting material and; b) basicity of the pyridine ligand. While the cut-off values of solubility and basicity presented here are specific to this system, the criteria are likely general, i.e. that the more basic a ligand, the more likely it is to form a complex and if the ligand is less soluble than other potential product phases, then complex formation is less likely. We have been able to rationalise the formation of a range of complexes using mono- and polypyridines by these observations, which will allow us to design further complexes to impart specific properties through the ligand. Other factors undoubtedly play a part in the likelihood of complex formation, such as hydrogen bonding and intramolecular interactions through coordination bonds. The former leads to the stabilisation of the complex with 4-inam and the latter to the 4-cnpy complex. Other intramolecular forces aid in crystallisation of the complexes presented here, which are more subtle and harder to predict, but do not seem to interfere too strongly with the effect of ligand solubility and basicity. Going forward, we aim to undertake further studies into this and other related systems to understand the limitations of the ideas presented here in predicting complex formation and aim to gain a high degree of control over the process.

\section{Experimental}

\section{Experimental methods}

Reagents were obtained from commercial suppliers and used without further purification. Single crystal X-ray diffraction data were collected at $100 \mathrm{~K}$ on a Rigaku AFC12 goniometer equipped with an enhanced sensitivity (HG) Saturn 724+ detector mounted at the window of an FR-E+ Superbright Mo K $\alpha$ rotating anode generator $(\lambda=0.71075 \AA$ ) with $\operatorname{VHF}(1$ and 8$)$ or $\operatorname{HF}(2-7,9,11)$ varimax optics. ${ }^{33}$ Unit cell parameters were refined against all data and an empirical absorption correction applied in CrysalisPro ${ }^{34}$ for (2-7A, 8, 10-15) or CrystalClear 3.1 b $27^{35}$ (7B and 9). All structures were solved by direct methods using SIR2011 ${ }^{36}(\mathbf{2})$, Superflip ${ }^{37-39}(\mathbf{3}, \mathbf{4}, \mathbf{6}, \mathbf{7 A}, \mathbf{9}, \mathbf{1 2}, \mathbf{1 4}, \mathbf{1 5})$ or $\operatorname{SHELXT}^{40}(\mathbf{5}, 7 \mathrm{~B}, \mathbf{8}, \mathbf{1 0}, \mathbf{1 1}, \mathbf{1 3})$ and refined on $F_{\mathrm{O}}^{2}$ by SHELXL$2013^{40}$ in OLEX2 $\vee 1.2 .{ }^{41}$ All hydrogen atoms were added in calculated positions and refined in riding mode on the parent atom. Data deposited with the CSD (CCDC 1907268-1907282). Elemental analysis was performed on an Exeter Analytical CE 440 elemental analyser.

\section{Example synthetic conditions}

A) Liquid pyridyl as solvent: $\left\{[\mathrm{Cu}(\mathrm{L})]_{2}\right\}_{n}(27.5 \mathrm{mg}, 0.05 \mathrm{mmol})$ was dissolved in $2 \mathrm{ml} 4$-picoline in a vial and $1 \mathrm{ml}$ water added. The vial was placed in a container with a further $10 \mathrm{ml}$ water and allowed to stand for three days to give brown needle crystals of 4. which were filtered and washed with $2 \times 2 \mathrm{ml}$ water. Yield $\mathrm{xx}$ mg (xx \%). $\mathrm{C}_{19} \mathrm{H}_{16} \mathrm{CuN}_{2} \mathrm{O}_{2}$ : Expected: $\mathrm{C}$ 62.03; $\mathrm{H} 4.38 ; \mathrm{N} 7.61$. Found: C 62.04; H 4.36; N 7.62. 
B) DMSO as solvent: $\left\{[\mathrm{Cu}(\mathrm{L})]_{2}\right\}_{n}(27.5 \mathrm{mg}, 0.05 \mathrm{mmol})$ and $24-$ bipy (15.6 mg, $0.05 \mathrm{mmol}$ ) were dissolved in $7 \mathrm{ml}$ DMSO at a hotplate temperature of $170{ }^{\circ} \mathrm{C}$, allowed to cool and left open to air. Dark green-black crystals of 6 formed over two days which were filtered, washed with $2 \times 2 \mathrm{ml} \mathrm{8:2} \mathrm{DMSO} / \mathrm{H}_{2} \mathrm{O}$ and 2 $\times 2 \mathrm{ml}$ water and left to dry in a desiccator. Yield $28.9 \mathrm{mg}(67 \%)$. $\mathrm{C}_{23} \mathrm{H}_{17} \mathrm{CuN}_{3} \mathrm{O}_{2}$ : Expected: $\mathrm{C}$ 64.10; $\mathrm{H}$ 3.98; $\mathrm{N}$ 9.75. Found: $\mathrm{C}$ 63.62; H 3.88; N 9.47.

\section{Conflicts of interest}

There are no conflicts to declare.

\section{Acknowledgements}

The authors would like to thank Dr Jonathon Beves (University of New South Wales) for his advice on the early draft of this manuscript.

This research was supported by a Marie Curie International Incoming Fellowship (TDK) within the seventh European Community Framework Program (grant PIIF-GA-2011- 300462).

\section{Notes and references}

1 C. Kaes, A. Katz and M. W. Hosseini, Chem. Rev., 2000, 100, 35533590.

2 R. D. Hancock, Chem. Soc. Rev., 2013, 42, 1500-1524.

3 K. Biradha, M. Sarkar and L. Rajput, Chem. Commun., 2006, 41694179.

4 M. D. Hill, Chem. Eur. J., 2010, 16, 12052-12062.

5 M. Baumann and I. R. Baxendale, Beilstein J. Org. Chem., 2013, 9, 2265-2319.

6 N. Elgrishi, M. B. Chambers, X. Wang and M. Fontecave, Chem. Soc. Rev., 2017, 46, 761-796.

7 D. Z. Zee, T. Chantarojsiri, J. R. Long and C. J. Chang, Acc. Chem. Res., 2015, 48, 2027-2036.

8 R. S. Khnayzer, V. S. Thoi, M. Nippe, A. E. King, J. W. Jurss, K. A. El Roz, J. R. Long, C. J. Chang and F. N. Castellano, Energy Environ. Sci., 2014, 7, 1477-1488.

9 B. R. Mullaney, L. Goux-Capes, D. J. Price, G. Chastanet, J. F. Létard and C. J. Kepert, Nat. Commun., , DOI:10.1038/s41467017-00776-1.

10 H. L. C. Feltham, M. G. Cowan, J. A. Kitchen, G. N. L. Jameson and S. Brooker, Supramol. Chem., 2018, 30, 296-304.

11 N. C. Anastasiadis, C. D. Polyzou, G. E. Kostakis, V. Bekiari, Y. Lan, S. P. Perlepes, K. F. Konidaris and A. K. Powell, Dalton Trans., 2015, 44, 19791-19795.

12 Z. A. Siddiqi, A. Siddique, M. Shahid, M. Khalid, P. K. Sharma, Anjuli, M. Ahmad, S. Kumar, Y. Lan and A. K. Powell, Dalton Trans., 2013, 42, 9513.

13 D. Z. T. Mulrooney, J. E. Clements, D. J. Ericsson, J. R. Price, I. A. Kühne, S. J. Coles, C. J. Kepert and T. D. Keene, Eur. J. Inorg Chem., 2018, 2018, 5223-5228.

14 T. D. Keene, M. J. Murphy, J. R. Price, N. F. Sciortino, P. D. Southon and C. J. Kepert, Dalton Trans., 2014, 43, 14766-71.

15 T. D. Keene, M. J. Murphy, J. R. Price, D. J. Price and C. J. Kepert,
Dalton Trans., 2011, 40, 11621.

16 W. A. Maza, A. J. Haring, S. R. Ahrenholtz, C. C. Epley, S. Y. Lin and A. J. Morris, Chem. Sci., 2016, 7, 719-727.

17 Z. Yin, Y. L. Zhou, M. H. Zeng and M. Kurmoo, Dalton Trans., 2015, 44, 5258-5275.

18 F. E. Poynton, S. A. Bright, S. Blasco, D. C. Williams, J. M. Kelly and T. Gunnlaugsson, Chem. Soc. Rev., 2017, 46, 7706-7756.

19 C. J. Cardin, J. M. Kelly and S. J. Quinn, Chem. Sci., 2017, 8, 47054723.

20 S. V. F. Beddoe, A. J. Fitzpatrick, J. R. Price, N. Mallo, J. E. Beves, G. G. Morgan, J. A. Kitchen and T. D. Keene, Cryst. Growth Des., 2017, 17, 6603-6612.

21 P. Pfeiffer, T. Hesse, H. Pfitzner, W. Scholl and H. Thielert, J. Prakt. Chemie, 1937, 149, 217-296.

22 A. Elmali, O. Atakol, I. Svoboda and H. Fuess, Z. Krist. Cryst. Mater., 1993, 205, 146-148.

23 L. Dexin, C. Xuegui and L. Fengling, Chinese J. Inorg. Chem., 1990, 6, 324-328.

24 D. S. Bohle and D. Stasko, Acta Crystallogr., 2002, E58, m340m341.

25 E. Labisbal, J. A. Garcia-Vazquez, J. Romero, S. Picos, A. Sousa, A. Castiñeiras and C. Maichle-Mössmer, Polyhedron, 1995, 14, 663670.

26 M. K. Koley, S. U. Parsekar, N. Duraipandy, M. S. Kiran, B. Varghese, P. T. Manoharan and A. P. Koley, Inorg. Chim. Acta, 2018, 478, 211-221.

27 W. P. Jencks and J. Regenstein, Handbook of Biochemistry and Molecular Biology, Fourth Edition, CRC Press, Boca Raton, 4th edn., 2010.

28 C. Hansch, A. Leo and R. W. Taft, Chem. Rev., 1991, 91, 165-195.

29 D. D. Perrin, B. Dempsey and E. P. Serjeant, $p K$ a Prediction for Organic Acids and Bases, Springer Netherlands, Dordrecht, 1981.

30 J. Clark and D. D. Perrin, Q. Rev. Chem. Soc., 1964, 18, 295.

31 Í. de S. Moreira, L. T. de S. Parente and D. W. Franco, Quim. Nova, 1998, 21, 545-550.

32 A. R. Katritzky, D. J. Short and A. J. Boulton, J. Chem. Soc., 1960, 1516.

33 S. J. Coles and P. A. Gale, Chem. Sci., 2012, 3, 683-689.

34 CrysAlisPro, Agilent Technologies, Version 1.171.3.

35 CrystalClear-SM Expert 3.1 b27, Rigaku, 2013.

36 M. C. Burla, R. Caliandro, M. Camalli, B. Carrozzini, G. L. Cascarano, C. Giacovazzo, M. Mallamo, A. Mazzone, G. Polidori and R. Spagna, J. Appl. Crystallogr., 2012, 45, 357-361.

37 L. Palatinus and A. van der Lee, J. Appl. Crystallogr., 2008, 41, 975-984.

38 L. Palatinus, S. J. Prathapa and S. van Smaalen, J. Appl. Crystallogr., 2012, 45, 575-580.

39 L. Palatinus and G. Chapuis, J. Appl. Crystallogr., 2007, 40, 786790.

40 G. M. Sheldrick, Acta Crystallogr., 2015, A71, 3-8.

41 O. V. Dolomanov, L. J. Bourhis, R. J. Gildea, J. A. K. Howard and H. Puschmann, J. Appl. Crystallogr., 2009, 42, 339-341. 